\title{
Dementia resulting from traumatic brain injury
}

\author{
Joana Ramalho ${ }^{1}$, Mauricio Castillo
}

\begin{abstract}
Traumatic brain injury (TBI) represents a significant public health problem in modern societies. It is primarily a consequence of traffic-related accidents and falls. Other recently recognized causes include sports injuries and indirect forces such as shock waves from battlefield explosions. TBI is an important cause of death and lifelong disability and represents the most well-established environmental risk factor for dementia. With the growing recognition that even mild head injury can lead to neurocognitive deficits, imaging of brain injury has assumed greater importance. However, there is no single imaging modality capable of characterizing TBI. Current advances, particularly in MR imaging, enable visualization and quantification of structural and functional brain changes not hitherto possible. In this review, we summarize data linking TBI with dementia, emphasizing the imaging techniques currently available in clinical practice along with some advances in medical knowledge.
\end{abstract}

Key words: craniocerebral trauma, chronic traumatic encephalopathy, post-concussion syndrome, dementia, magnetic resonance.

\section{DEMÊNCIA RESULTANTE DE TRAUMATISMO CRÂNIO-ENCEFÁLICO}

RESUMO. 0 traumatismo cranioencefálico (TCE) representa um importante problema de saúde pública nas sociedades modernas. As suas principais causas são: os acidentes de trânsito e as quedas. 0 traumatismo leve e repetido relacionado com os esportes de contato ou o traumatismo relacionado com as ondas de choque provenientes de explosões em cenário de guerra são hoje reconhecidas como importantes causas de TCE. A mortalidade e morbilidade associada ao TCE é considerável. TCE representa o fator de risco ambiental melhor reconhecido para o desenvolvimento de demência. Com o reconhecimento recente de que até o TCE leve pode determinar déficts cognitivos, os estudos de imagem adquiriram grande importância neste contexto. Contudo, não está definido qual o melhor estudo de imagem para caracterizar o TCE. Avanços tecnológicos, como a ressonância magnética, permitem atualmente identificar e quantificar alterações intraparenquimatosas estruturais e funcionais, não detectáveis nos estudos convencionais. Neste artigo os autores resumem os estudos que relacionam TCE e demência, dando particular ênfase às técnicas de imagem atualmente disponíveis na prática clínica, bem como alguns avanços nos métodos de imagem ainda limitados ao plano da investigação.

Palavras-chave: traumatismo cranioencefálico, encefalopatia crônica pós-traumática, síndrome pós-concussão, demência, ressonância magnética.

\section{INTRODUCTION}

Traumatic brain injury (TBI) is a com-

1 mon clinical problem that represents a major source of morbidity and mortality in the modern era. The most common causes of head injury are motor vehicle accidents and falls. TBI is commonly classified as mild, moderate or severe, depending on whether the injury causes unconsciousness, how long unconsciousness lasts and the severity of symptoms. Although most TBIs are classified as mild because they are not life-threatening, even a mild TBI can have serious and longlasting effects. One of the most feared longterm consequence of TBI is dementia, since a number of epidemiologic studies have shown that experiencing a TBI in early or midlife is associated with an increased risk of dementia in later life. ${ }^{1}$ Common areas of cognitive impairment caused by TBI include memory,

This study was conducted at the University of North Carolina at Chapel Hill, Chapel Hill, NC, US.

${ }^{1}$ Centro Hospitalar de Lisboa Central, Lisboa, Portugal; University of North Carolina at Chapel Hill, Chapel Hill, NC, US. ${ }^{2}$ University of North Carolina at Chapel Hill, Chapel Hill, NC, US.

Joana Ramalho. Alameda de Santo António dos Capuchos - 1169-050 Lisboa - Portugal. E-mail: joana-ramalho@netcabo.pt

Disclosure: The authors report no conflits of interest.

Received September 13, 2015. Accepted in final form November 15, 2015. 
information processing speed, attention and executive function, with many TBI patients experiencing degradation in all four even when their TBIs have been classified as mild. ${ }^{2}$ It has also been observed that repetitive mild head trauma, as experienced by professional boxers, football and hockey players, is associated with a high risk of chronic traumatic encephalopathy (CTE) a type of dementia with distinctive clinical and pathologic features. The recent recognition that a similar syndrome may occur in military personnel, who also experience high rates of mild TBI, has rekindled interest in this condition. ${ }^{1}$

Long-term cognitive deficits may occur despite normal-appearing brain on conventional neuroimaging studies, such as computed tomography (CT) and magnetic resonance (MR) imaging. In this setting, advanced MR techniques, including susceptibility-weighted imaging (SWI), diffusion-weighted imaging (DWI), perfusionweighted imaging (PWI), magnetization transfer MRI (MT), magnetic resonance spectroscopy (MRS), diffusion tensor imaging (DTI) and functional blood oxygen level-dependent MRI (fMRI) may shed light on subtle but important findings in TBI. Other promising neuroimaging tools include positron emission tomography (PET), single photon emission tomography (SPECT) and magnetoencephalography (MEG). Our aim was to review data linking TBI with dementia and to summarize the brain-imaging techniques currently available in clinical practice along with some future imaging trends.

\section{DEFINITION/CLASSIFICATION}

TBI occurs when an outside force hits the head hard enough to cause the brain to move violently within the skull disrupting normal brain function. According to whether the injury causes unconsciousness and how long unconsciousness lasts, brain injury may be classified as mild (mTBI) when no loss of consciousness occurs or unconsciousness lasts less than 30 minutes, moderate when unconsciousness lasts more than 30 minutes and severe if unconsciousness lasts more than 24 hours. TBI can also be classified using the Glasgow coma scale (GCS) as mild (GCS=13-15), moderate (GCS=9-12) and severe $(G C S<8)$. However, defining minor versus major head injuries is complex. Some authors suggest major injury as worsening level of consciousness, loss of consciousness for more than $5 \mathrm{~min}$, focal neurological findings, seizure, failure to improve in mental status over time, penetrating skull injuries, signs of a basal or depressed skull fracture, and confusion or aggression on examination. ${ }^{3-8}$

Post-concussion syndrome (PCS) refers to a set of nonspecific symptoms that may last for weeks, months, or years after a concussion. Its most common symptoms include headache, dizziness, difficulty concentrating, irritability, and sleep problems. Loss of consciousness is not required for a diagnosis of concussion or post-concussion syndrome. In most patients, post-concussion syndrome symptoms occur within the first seven to 10 days and resolve within three months but can persist for a year or longer.

Dementia is a loss of mental ability sufficiently severe to interfere with normal activities of daily living, lasting more than six months, not present at birth and not associated with a loss or alteration of consciousness. Indeed, dementia is not a single disease but an umbrella term covering a wide range of medical conditions that have in common a group of symptoms caused by gradual death of brain cells. The loss of cognitive abilities that occurs with dementia leads to impairments in memory, reasoning, planning and behavior. Brain changes that cause dementia may be temporary, but are more often permanent and worsen over time, leading to increasing disabilities and a shortened lifespan. ${ }^{9}$

Chronic traumatic encephalopathy (CTE) is a progressive degenerative disease associated with history of repetitive brain trauma including symptomatic concussions and asymptomatic subconcussive impacts to the head. This type of dementia was initially recognized in professional boxers by Harrison S. Martland in 1928, ${ }^{10}$ who described a group of signs and symptoms called dementia pugilistica. Currently CTE can only be definitively diagnosed postmortem and is classified as a distinct entity in the category of tauopathy. Tauopathies are characterized by dissociation of tau proteins from microtubules, which are hyperphosphorylated and aggregate to form neurofibrillary tangles (NFTs), a process that presumably serves as the instigator of toxicity and cell death by unknown mechanisms. CTE has been confirmed at autopsy in football, soccer, ice hockey, and other contact sports athletes who have an inherent risk of subconcussive or concussive injuries. ${ }^{1,11,12}$

\section{EPIDEMIOLOGY}

An estimated 10 million people are affected annually by TBI worldwide. ${ }^{13}$ However, this figure is likely underestimated because it does not include patients with mTBI who frequently dismiss their symptoms and never seek medical attention (25\%) or those who are seen in private clinics or by primary care physicians $(14 \%)$ that do not report the clinical findings. ${ }^{14,15}$ The Centers for Disease Control and Prevention (CDC) estimate that 1.7 million Americans annually experience TBI severe 
enough to cause death or require emergency room care or hospitalization and that 5.3 million (almost $2 \%$ of the population) are living with some degree of TBI-related disabilities. ${ }^{1}$ According to the World Health Organization, TBI will surpass many diseases as the major cause of death and disability by the year 2020.13,16 Based on the large number of known and likely unknown cases, traumatic brain injury has been referred to as the "silent epidemic". ${ }^{17}$ Recently, the public has become more aware of TBI through news reports of sports injuries leading to long-term effects of repetitive trauma to the brain as well as news reports about soldiers returning from Iraq and Afghanistan with TBI which is now being called the "signature injury of war". ${ }^{18,19}$ These patients further increase the number of unaccounted cases of mild TBI since they do not seek medical attention in the belief that admission of symptoms may jeopardize their careers. ${ }^{20,21}$

It is estimated that $75-90 \%$ of all treated brain injuries are mild corresponding to an expected incidence of 100-300/100,000 cases according to the WHO task force. ${ }^{22}$ It has been proposed that as many as one in three mTBI victims have persistent long-term cognitive deficits, ${ }^{23,24}$ which can occur despite normal results on conventional neuroimaging studies. Based on currently available data, a rough calculation of how much of the population's burden of dementia is attributable to TBI suggests a risk of dementia attributable to TBI of $5 \%-15 \%{ }^{1,25}$

\section{ETIOLOGY}

Leading causes of TBI in the general population include falls, motor vehicle collisions, assaults, and sportsrelated injuries. ${ }^{21}$ Falls are the leading cause of TBI in all ages. Those aged 75 years and older have the highest rates of TBI-related hospitalization, long-term cognitive changes, and death due to falls. Other recently recognized causes of TBI are repetitive head trauma resulting from contact sports, and combat-related head injuries seen in soldiers returning from war. ${ }^{18}$ In addition, TBI can result from bullet wounds or other injuries that penetrate the skull and brain.

TBI is a heterogeneous group of injuries with complex relationships with the mechanism of injury and timing of the forces impacting the skull and body. There are two common assumptions regarding the etiology of mTBI. The first is that the frontal and anterior cortices are vulnerable to neural contusion (Figure 1). The second is that linear and rotational forces act on axon bundles leading to axonal injury ${ }^{26-29}$ (Figures 2 and 3). After the initial injury, secondary mechanisms elicit biochemical, metabolic and cellular changes over the course of minutes, days and months. ${ }^{30,31}$

Traumatic brain injury is the most well-established environmental risk factor for dementia. Currently available data suggest: (I) sufficient evidence of an association between moderate/severe TBI and dementia, with an increased risk of dementia of between 2-and 4-fold for these patients; (II) limited evidence of an association between mild TBI with loss of consciousness and

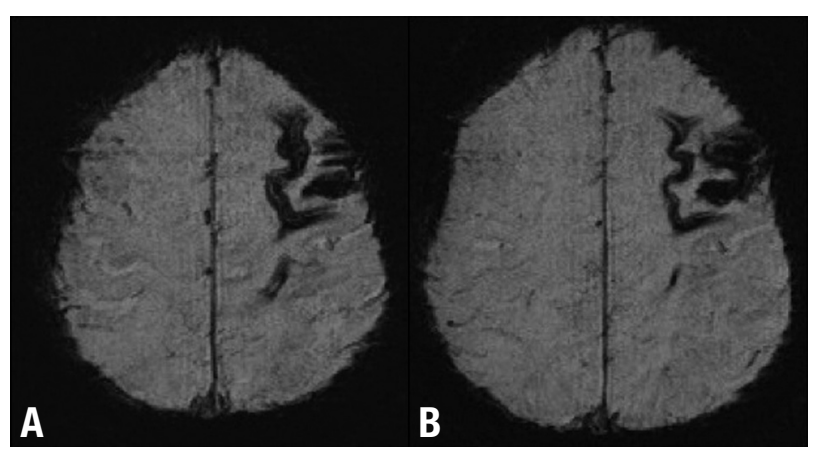

Figure 1. Patient with mild cognitive decline after moderate TBI. MR Susceptibility-weighted imaging (SWI) axial images [A and B] show frontal contusion and superficial siderosis seen as cortical low signal intensity lines over the cortex due to subarachnoid hemorrhage.

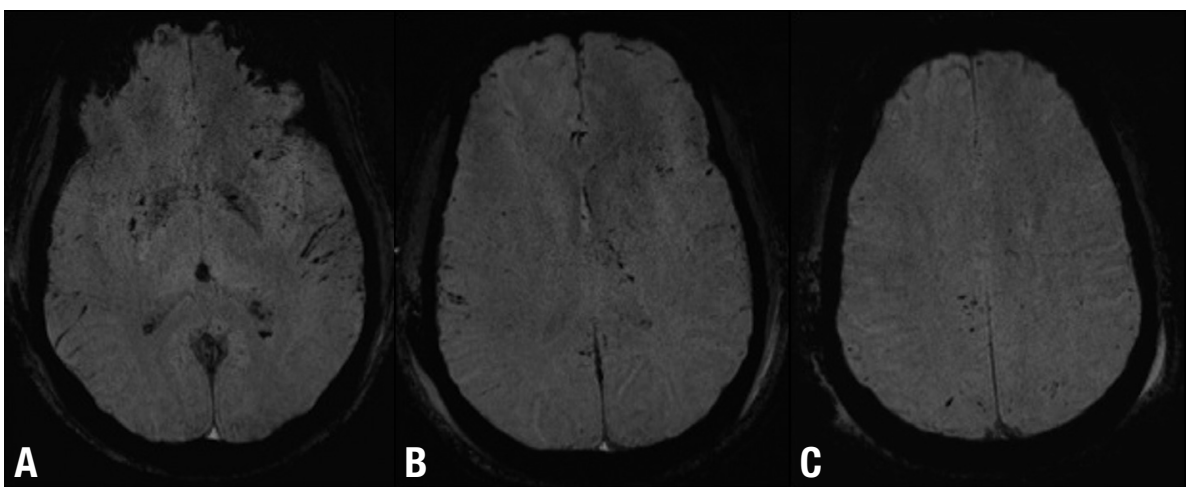

Figure 2. DAl and subarachnoid hemorrhage after mild TBI. Axial SWI [A, B and C] show multiple focal lesions involving the basal ganglia and the lobar white matter at the gray-white matter interface. Note also the bilateral subarachnoid hemorrhage particularly evident in the left sylvian fissure. 


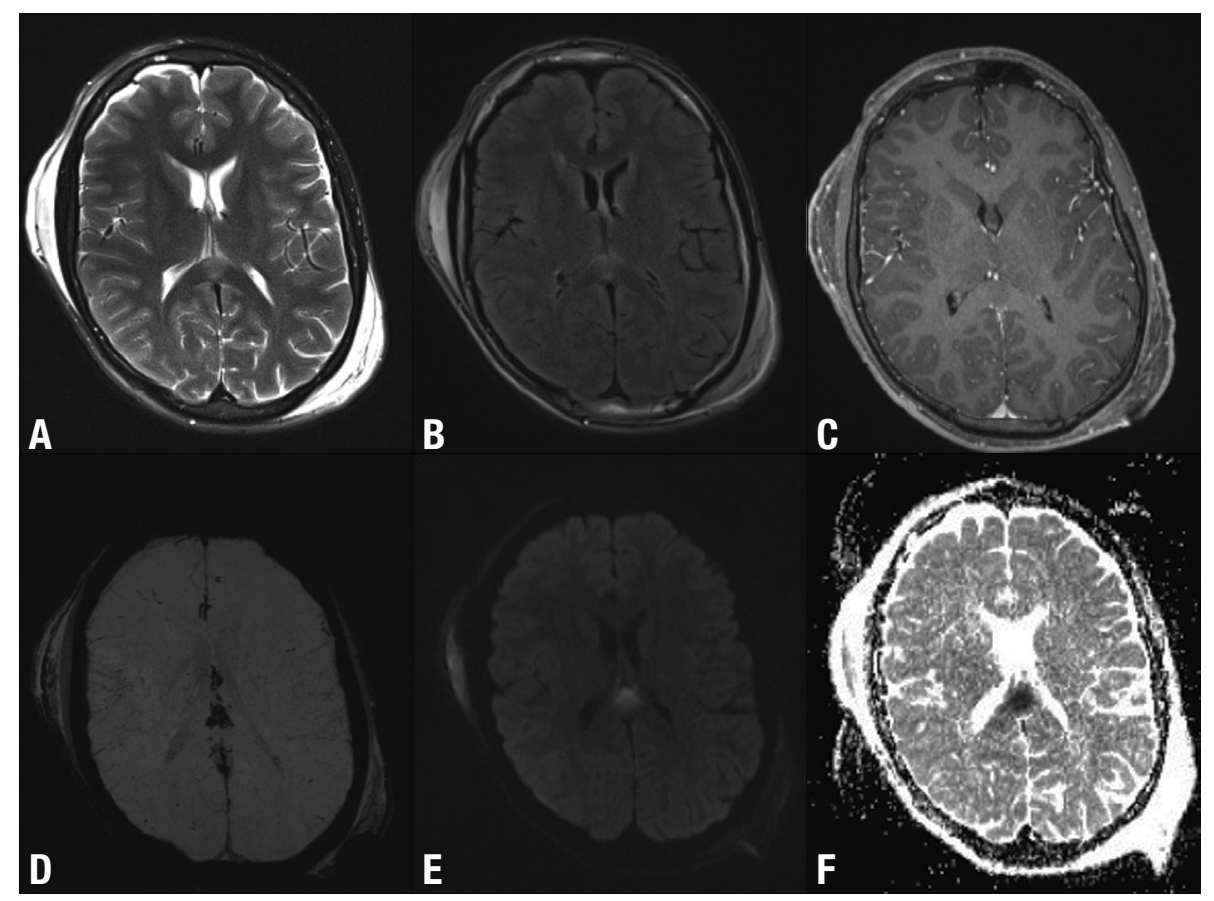

Figure 3. DAl involving the splenium of the corpus callosum after TBI. Axial T2weighted $[A]$, FLAIR $[B]$, post-contrast T1-weighted [C], SWI [D], DWI [E] and $A D C$ map $[F]$ show high signal lesion T2-weighted $[A]$ and FLAIR $[B]$ images, with no enhancement after gadolinium administration [C], low signal on SWI [D] and restricted diffusion (high signal on DWI [E] and low signal on ADC map). MRI is the modality of choice for assessing suspected diffuse axonal injury even in patients with entirely normal CT of the brain. Note also the bilateral subgaleal haematomas. dementia; (III) and inadequate/insufficient evidence to determine whether an association exists between mild TBI without loss of consciousness and dementia. ${ }^{1,32}$ There is no evidence that a single mild TBI episode increases dementia risk. However, as stated before, it is accepted that multiple repetitive mTBIs, as observed in professional boxers, retired professional football, hockey and soccer players and other contact sports players, may have serious long-term consequences. ${ }^{33}$ The risk of dementia in boxers seems most closely tied to the number of rounds boxed, not to the number of times a boxer was knocked out, suggesting that even repeated mild TBIs that do not cause unconsciousness may increase dementia risk. ${ }^{9}$ Additionally, it has been proven that a number of sub-concussive events may be as damaging as a frank concussion. $^{34}$

\section{PATHOPHYSIOLOGY}

TBI initiates an inflammatory cascade that results in the release of amino acids, such as glutamate and aspartate, and free radicals that lead to tissue damage. ${ }^{35}$ Other potential culprits include nitrous oxide, endogenous opioid peptides such as naloxone, catecholamines, acetylcholine, thyrotropin-releasing hormone (TRH), lactate, and adenosine. ${ }^{36,37}$ Cytokines such as tumor necrosis factor (TNF) and interleukins 1,6, and 8, have also been found to increase following TBI. ${ }^{38}$ PET, functional MRI, MR spectroscopy, and SPECT, may play a crucial role in identifying the concentrations and loca- tions of some of these molecules in animal and human brains following injury. ${ }^{8}$

The diffuse axonal injury (DAI) which can occur after severe, moderate and mTBI is an important neuropathological consequence of brain trauma. DAI involves a number of abnormalities ranging from direct damage to the axonal cytoskeleton to secondary damage from disruption of axoplasmic membrane transport, proteolysis, and swelling. ${ }^{39}$ For instance, ionic imbalances, through an efflux of potassium and influx of sodium, lead to calcium influx into cells resulting in mitochondrial damage and impaired oxidative metabolism with lactate production. ${ }^{16,40,41}$

Several investigators have studied the relationship between inheritance of the apolipoprotein $\varepsilon 4$ (APOE $\varepsilon 4$ ) allele and dementia (particularly Alzheimer disease) after TBI, with conflicting results. In a population-based study in Northern Manhattan, New York ${ }^{42}$ a history of TBI and inheritance of an APOE $\varepsilon 4$ allele were associated with a 10-fold increased risk of dementia while APOE $\varepsilon 4$ in the absence of TBI resulted in only a 2-fold increased risk of dementia. The study found no increased risk of dementia due to TBI in the absence of APOE $\varepsilon 4$. Similarly, in a prospective study of World War II veterans, ${ }^{43}$ there was a non-significant trend toward higher dementia risk in APOE $\varepsilon 4$ carriers. Conversely, in the MIRAGE study, ${ }^{44}$ the influence of head injury on the risk of dementia was greater among persons lacking APOE $\varepsilon 4$ compared with those having one or two APOE $\varepsilon 4$ alleles. ${ }^{1}$ 


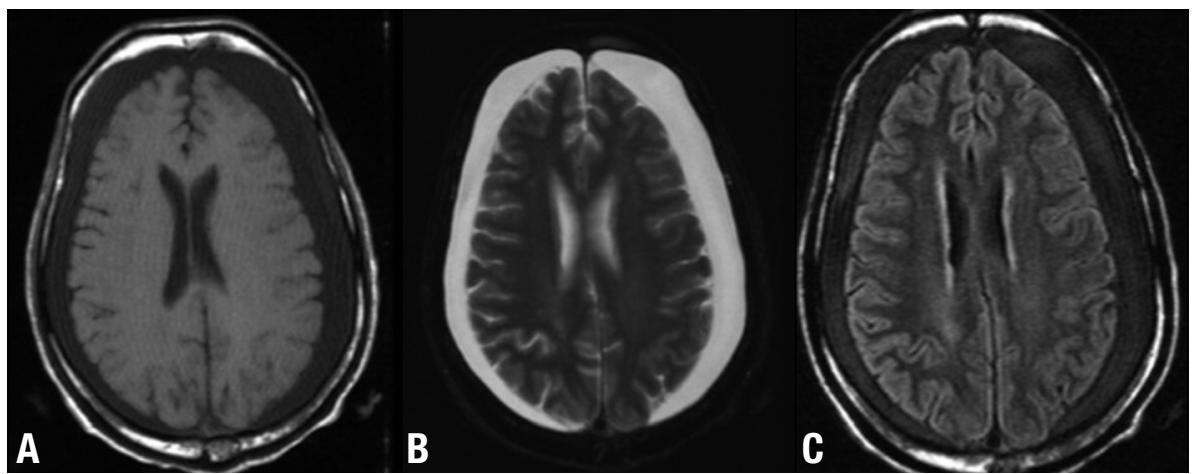

Figure 4. Cognitive decline 8 weeks after TBI. Axial T1-weighted [A], T2weighted $[B]$ and FLAIR $[C]$ images show bilateral chronic subdural hematomas with no midline shift.

\section{PATHOLOGY}

In rodent models, TBI resulted in neurodegeneration and progressive brain atrophy that continued for at least 1 year after injury. ${ }^{1,45}$ Several proteins associated with neurodegenerative disease in humans have also been demonstrated to accumulate following experimental TBI in rodents. Amyloid precursor protein is upregulated immediately after TBI and $\beta$-amyloid peptide accumulates over weeks and months after trauma. ${ }^{46-48} \beta$-Secretase, presenilin 1 , and caspase 3 also accumulate for up to 6 months after injury. ${ }^{47}$ In triple transgenic mice expressing pathogenic mutations in amyloid precursor protein, pre-senilin 1 and tau, TBI resulted in accumulations of intra-axonal $\beta$-amyloid peptide and hyperphosphorylated tau which persisted for up to 1 week after injury. ${ }^{49}$ These findings have led to the hypothesis that $\beta$-amyloid peptide and tau accumulation are important mechanisms in the long-term neurodegenerative effects of TBI. This hypothesis has important therapeutic implications as recent developments in Alzheimer disease (AD) therapeutics, such as anti- $\beta$-amyloid antibodies, inhibitors of $\beta$ - secretase or $\gamma$-secretase activity, or other amyloid- or tau-targeted therapies ${ }^{50,51}$ may have potential roles in the management of TBI. ${ }^{1}$

Additional evidence indicating that neurodegeneration after TBI shares some features with $\mathrm{AD}$ has been noted on imaging studies. Cerebral atrophy after TBI is not diffuse but rather regionally selective, and the regions that show the most prominent atrophy after TBI, such as the hippocampus, amygdala, precuneus, and parietal and frontal cortices, closely overlap with regions of predominant $\beta$-amyloid deposition, decreased glucose uptake, and progressive atrophy in AD. ${ }^{52}$ These findings may be related to common molecular mechanisms shared between $\mathrm{AD}$ and TBI-related neurodegeneration., ${ }^{1,8}$ However, $\mathrm{AD}$ and CTE are distinct entities. Recent studies in retired professional athletes who had sustained multiple concussions and developed dementia, reported prominent tau-immunoreactive NFTs and astrocytic tangles, but $\beta$-amyloid pathology was noted in less than half of the cases. ${ }^{1,11}$ There is also a characteristic distribution pattern of NFTs unique to CTE. The NFTs tend to concentrate in the medial temporal cortex, hippocampus and parahippocampal gyrus, thalamus, mammillary bodies, amygdala, hypothalamus, and substantia nigra. The NFTs also preferentially accumulate in the depths of sulci and surround small blood vessels and in the ventricles in an irregular, patchy distribution. In the neocortices, NFTs concentrate in superficial layers II and III, differing from AD in which NFTs predominate in the deeper layers $\mathrm{V}$ and VI. Also unlike AD, there is a paucity of neuritic plaques in CTE. ${ }^{1,11}$

\section{CLINICAL FINDINGS}

The severity of symptoms depends on whether the injury is mild, moderate or severe. Symptoms often appear at the time of the injury or soon after, but sometimes may not develop for days or weeks. In all levels of TBI, cognitive changes are among the most common, long-lasting and disabling (Figure 4). The ability to learn and remember new information is often affected. Other commonly affected thinking skills include the capacity to pay attention, organize thoughts, plan effective strategies for completing tasks and activities, and make sound judgments. ${ }^{9}$

There is a misconception that loss of consciousness must occur to be characterized as mTBI. As a result, many people with mTBI do not seek help and many health care professionals do not recognize that mTBI has occurred. ${ }^{16}$ Indeed, the term "mild TBI" is actually a misnomer since serious short and long term effects are associated. Individuals with an initial GCS score of 13-15 are acutely at risk for intracranial bleeding and diffuse axonal injury ${ }^{53}$ (Figure 2). Additionally, after a concussion, a minority of patients have persistent disabling symptoms known 
as post-concussion syndrome (PCS). The rates of PCS vary but most studies report that about $15 \%$ to $30 \%$ of individuals with a history of a single concussion develop persistent symptoms associated with the injury. The nature of symptoms in PCS may change over time and acute symptoms are most commonly of a physical nature while persistent symptoms tend to be predominantly psychological. Headache and dizziness usually occur immediately after the injury but can also be long lasting. PCS is a clinical diagnosis that is difficult to establish since most symptoms are similar to those experienced by individuals diagnosed with depression, chronic pain, anxiety, or post-traumatic stress disorder. ${ }^{1,54}$ Some experts believe post-concussion symptoms are caused by structural damage to the brain or disruption of neurotransmitter systems resulting from the impact that caused the concussion. Others believe that post-concussion symptoms are related to psychological factors.

PCS should not be confused with CTE. Clinical symptoms of CTE are only beginning to be understood. They are thought to include changes in mood (i.e. depression, suicidality, apathy, anxiety), cognition (i.e. memory loss, executive dysfunction), behavior (i.e. short fuse, aggression), and in some patients, motor disturbances (i.e. difficulty with balance and gait). Differentiating between prolonged PCS and CTE symptoms can be difficult.

\section{DIAGNOSIS}

The diagnosis of TBI in the acute setting is based on neurological examination and neuroimaging tools such as CT and MR imaging. While CT may be critically important in the first 24 hours to assess the immediate need for neurosurgical intervention, MR imaging is more sensitive for detecting small and subtle abnormalities not detected by CT. ${ }^{19}$

In the chronic management of head trauma, imaging has several potential roles such as identifying postoperative neurophysiological sequelae, evaluating the underlying functional abnormalities associated with late complications of head trauma, predicting long-term prognosis, guiding rehabilitation, and developing new therapies to prevent secondary injury. ${ }^{8,19}$

Mild TBI is difficult to diagnose because the brain often appears normal on conventional CT and MR imaging. This lack of imaging evidence of brain injury in mTBI has led clinicians to typically diagnose it on the basis of clinical and cognitive symptoms, which are generally self-reported and are non-specific. ${ }^{53}$ The symptoms may be the result of subtle neurological alterations that are beneath the threshold of what can be detected using conventional neuroimaging techniques. ${ }^{1,19}$ Unlike PCS in which the diagnosis is clinical, CTE diagnosis can only be made at brain autopsy.

Research studies are currently examining whether neuroimaging can detect subtle changes in axonal integrity and structural lesions that can occur in mTBI. Recently, further progress in in-vivo diagnostic techniques has been made, particularly with MR imaging advanced techniques. However, more research needs to be done before any such techniques can be validated. ${ }^{1,21,54,55}$

\section{IMAGING FINDINGS}

MR imaging. MR imaging of morphometric abnormalities in patients with mTBI has been extensively studied. Generalized brain atrophy is commonly reported and seems to be a common finding in more severely affected patients. ${ }^{56-64}$ Reductions in volume in specific brain regions have been observed including in the hippocampus ${ }^{65-68}$ amygdalas, ${ }^{63}$ fornices, ${ }^{58,68}$ thalamus, ${ }^{63,67}$ and regions of the cingulate gyrus, ${ }^{59,60,64,67}$ as well as enlargements of the lateral ventricles, temporal horns and/or ventricular-to-brain ratio. ${ }^{58,65,66,69}$ Reduced volume in subcortical gray matter regions ${ }^{58}$ and an overall reduction in white matter have also been reported. ${ }^{57,60,70}$ Ding et al. ${ }^{57}$ noted that the changes in white and gray matter over time correlated with acute diffuse axonal injuries and that the latter predicted post-injury cerebral atrophy. ${ }^{19}$

DAI is an important consequence of TBI. DAI is usually diffuse, bilateral and frequently involves the lobar white matter at the gray-white matter interface and may be reversible (Figures 2 and 3). Although DAI is rarely fatal, it can result in significant neurological impairment. The number of lesions correlates with poorer outcomes and lesions in the supratentorial white matter, corpus callosum and corona radiata correlate with a greater likelihood that the patient will remain in a persistent vegetative state. Whereas hemorrhagic axonal injury can be seen on $\mathrm{CT}$ as multiple foci of high attenuation, nonhemorrhagic injury can be missed. In fact, $\mathrm{CT}$ is abnormal in less than half of all patients with $\mathrm{DAI}^{8}$ (Figure 5).

Susceptibility weighted imaging (SWI) has a six-fold greater ability to detect hemorrhagic DAI than other MR imaging techniques. ${ }^{71,72}$ This technique is thus particularly appropriate for discerning micro-hemorrhages in TBI as it is sensitive to bleeding where small and subtle lesions are not discernible using other MR imaging techniques. This renders SWI particularly useful in the acute and subacute stages following brain trauma ${ }^{8,19}$ (Figure 6).

Diffusion-tensor imaging (DTI) is a relatively new neuroimaging technique that is sensitive to subtle 
changes in white matter fiber tracts and is capable of revealing microstructural axonal injuries, which may be potentially responsible for persistent post-traumatic symptoms. ${ }^{1,19}$

The concept underlying DTI is that the local profile of the diffusion in different directions provides important indirect information about the microstructure of the underlying tissues. In the white matter, axonal membranes, myelin sheaths, microtubules and neurofilaments restrict the movement of water. This restriction is dependent on the direction of the axons (i.e. diffusion is not equal in all directions). Water diffuses freely in directions parallel to axons but it is restricted in directions perpendicular to axons which results in the magnitude of the diffusion along axons being greater than the two perpendicular directions thus leading to an elongated ellipsoidal shape of the diffusion tensor described as "anisotropic." There are various ways that the shape and size of a diffusion ellipsoid can be quantified but the two most common indices used are Fractional Anisotropy (FA) for shape, and Mean Diffusivity (MD) for size. FA is a scalar measure that ranges from 0 to 1 , with 0 indicating complete isotropy meaning that water diffuses equally in all directions and 1 depicting the most extreme anisotropic scenario in which molecules are diffusing along a single axis. Accordingly, in normal white matter FA should be close to 1 and reduced FA is generally thought to reflect loss of white matter integrity. DTI, however, is somewhat non-specific when using these parameters and it is not known whether disruptions in FA and MD are the result of disturbances in axonal membranes, myelin sheath, microtubules, neurofilaments, or other factors.
Different DTI studies in TBI have shown that most of the abnormalities have a systematic spatial distribution corroborating previous suggestions that anterior regions of the brain are more vulnerable to post-traumatic abnormalities. ${ }^{54,73-75}$

Different studies support the hypothesis that acute mTBI is associated with elevated anisotropy values and chronic mTBI with depressed anisotropy. ${ }^{54,76,77}$ However, some studies have reported both trauma-related decreases and increases in FA, particularly in the subacute phase post-injury while many others have reported that FA values increase in both acute and chronic phases of injury. ${ }^{21}$ One possibility for the increase in FA acutely

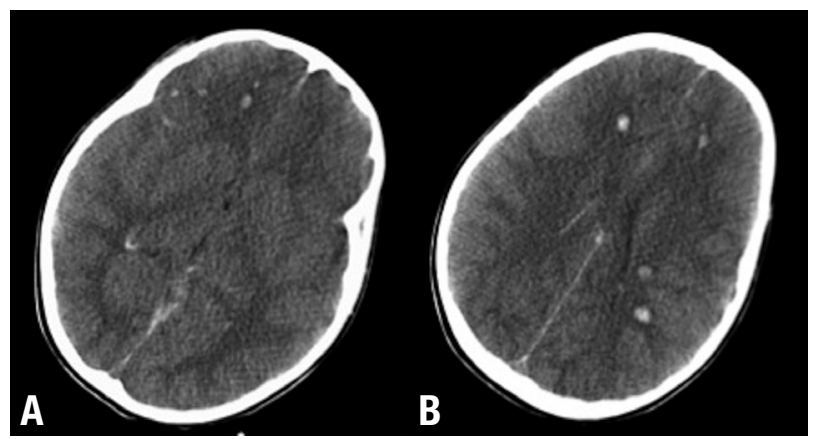

Figure 5. DAl in a patient with severe TBI. Axial non-contrast CT [A and $B]$ show multiple hyperdense lesions varying in size involving primarily the gray-white matter junction. Note that the appearance of DAI on CT depends on whether or not the lesions are hemorrhagic. Subtle or nonhemorrhagic DAl may be not detected on CT and such patients usually have relatively normal CT scans with significant unexplained neurological deficit.

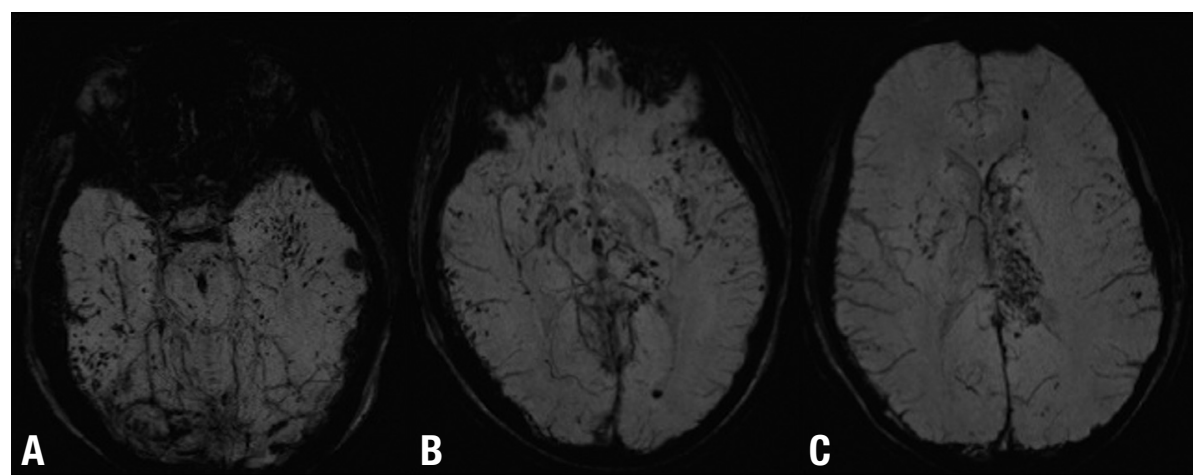

Figure 6. DAl after severe TBI (motor vehicle accident) well depicted on SWI. Axial SWI $[A, B$ and C] shows diffuse and bilateral lesions involving the basal ganglia, lobar white matter, gray-white matter junction, corpus callosum and the brainstem. SWI (or gradient echo sequences) are exquisitely sensitive to blood products and the best MR sequences for DAl detection. Note that when the DAl lesions are entirely nonhemorrhagic they will not be detected on these sequences, but the will be visible as areas of high FLAIR signal. 
is that MR diffusion-based measurements are not only sensitive to white matter microstructure but additionally are affected in the acute stage by inflammation, secondary injury (ischemia, cerebral hypoxia, and cerebral edema) and/or compensatory mechanisms. ${ }^{76,77}$ Chronically though, residual damage of white matter may lead to decreased anisotropy. Whatever the causative mechanism is, poor neuropsychological performance seems to be associated with high anisotropy scores immediately after injury and with low anisotropy in the chronic phase. $^{54}$

More specific measures to further delineate the biological meaning of alterations in white matter integrity are under investigation including Mode ${ }^{78}$ which more precisely defines the shape of the diffusion tensor (useful in distinguishing the anatomy of fiber tracts, including distinguishing fiber crossings from pathology); InterVoxel Coherence, ${ }^{79}$ which measures how similar anisotropic tensors are in neighboring voxels and is useful for measuring anomalies in macroscopic axonal organization within the tract of interest, and Axial and Radial Diffusivity which are purported to measure axonal and myelin pathology, respectively. Additional approaches include the free-water model ${ }^{80}$ by which it is possible to explicitly estimate the volume of extracellular water, a measure that is sensitive to vasogenic edema and therefore likely specific to neuro-inflammation; Multi-shell diffusion imaging which is a new approach where DWI is acquired at multiple b-values in the same session providing additional microstructural information about the organization of white and gray matter; and kurtosis which is a measure of the deviation from the diffusion tensor model (Gaussian diffusion) and thus complements the other measures derived from the tensor model. ${ }^{19}$ Other methods for resolving crossing fibers include the neurite orientation dispersion and density imaging model, ${ }^{81}$ Q-ball imaging ${ }^{82}$ and constrained spherical deconvolution. ${ }^{83}$ Further studies are required to determine which method is the best. ${ }^{21}$

A normative atlas of DTI-derived measures that depict anatomical variations in healthy controls can also be created so that individual cases may then be compared to discern the pattern of pathology. ${ }^{19}$

In summary, DTI is a promising neuroimaging technique that may help to identify axonal injury after mTBI, however, its role in routine clinical practice has not yet been established

Another promising technique is MR spectroscopy (MRS), which is able to quantify different brain metabolites including $\mathrm{N}$-acetylaspartate (NAA) for neuronal integrity, creatine $(\mathrm{Cr})$ for cellular energy/attenuation, choline (Cho) for membrane turnover, myoinositol an osmotic and gliosis marker, and lactate for anaerobic metabolism. NAA, creatinine, choline, and myoinositol seem to be sensitive to neuronal injury in DAI. In mild TBI, the most common finding is a widespread reduction in gray matter and white matter $\mathrm{NAA}^{21,56,84-87}$ and several investigators have found that lower NAA to creatine ratios correlate with poorer clinical outcomes.,88 Studies of MR spectroscopy in chronic mild TBI have found reductions in NAA in the splenium of the corpus callosum, ${ }^{89}$ centrum semiovale,${ }^{90}$ and frontal white matter. ${ }^{91}$ Chemical shift imaging ${ }^{92,93}$ and whole-brain NAA studies $^{92}$ have also demonstrated NAA reductions in white matter. However, disparity exists between studies in the quantification of Cho. Some studies have found increased Cho in various regions in the brain parenchyma, ${ }^{86,92,94}$ while others have reported the absence of statistical changes in Cho. ${ }^{87,93,95}$ Changes found in Cho, a marker for cellular proliferation and/or tissue damage may reflect diffuse axonal injury. ${ }^{90,92}$ In the acute phase of head injury, choline-containing metabolites may be released as a result of shear injuries and damage to both cell membranes and myelin. ${ }^{96}$ In chronic brain injury, the mechanism for increased Cho is more likely to be related to diffuse glial proliferation, as corroborated by elevated myoinositol that persists for months after injury. ${ }^{97}$ Recent studies have shown changes in $\mathrm{Cr}^{95,98}$ If $\mathrm{Cr}$ is affected by mild TBI, metabolite ratio measurements are not accurate because it is difficult to assess whether these changes are due to the metabolite of interest or to $\mathrm{Cr}$. There is significant heterogeneity in the literature and further research is needed to validate this technique for routine clinical use. ${ }^{21}$

MRS and DTI are complimentary given the biochemical and structural focus of each modality. However, few studies have utilized both together. In severe head injury, the combination of these two modalities provides greater diagnostic accuracy for predicting outcome one year following injury ${ }^{99}$ than either MRS or DTI alone. It is likely that this same combination could also provide greater sensitivity to subtle changes in mTBI. ${ }^{19}$

Different studies have used magnetization transfer MRI (MT) to detect white matter abnormalities in different diseases. Through MT, a magnetization transfer ratio can be derived and used quantitatively to measure the structural integrity of tissues. MT changes have been found to be more sensitive than T2-weighted MR imaging in detecting histologic axonal damage in animal models. ${ }^{100,101}$ Bagley et al. ${ }^{102}$ found associations between MT abnormalities and neurological deficits. ${ }^{8}$

Brain perfusion in patients with TBI has been done 
using different techniques, including stable xenonenhanced CT, single-photon emission CT (SPECT), PET, perfusion $C T$, and perfusion-weighted MR imaging (dynamic susceptibility contrast and arterial spinlabeling) ${ }^{21}$ Perfusion-weighted MR imaging is difficult to obtain in the acute setting due to patient contraindications but is an attractive imaging technique for the subacute and chronic phases especially because it can be combined with other MR imaging sequences sensitive to TBI lesions. ${ }^{21}$ In patients with mild TBI and normal conventional brain imaging, perfusion-imaging studies have shown scattered deficits, which correlate significantly with neuropsychological and neurocognitive impairments as well as posttraumatic amnesia (Figure 7). The potential benefits of perfusion imaging in the clinical management of patients with severe TBI have yet to be evaluated. However, patients with altered brain perfusion may be considered for more aggressive and early treatments to prevent intracranial hypertension, whereas patients with preserved brain perfusion may benefit from less invasive treatment. The majority of perfusion studies have involved only limited numbers of patients and further research is required to validate their findings and determine how relevant they are in the management of individual patients with TBI. ${ }^{21}$

Blood oxygen level-dependent (BOLD) fMRI methods for investigating TBI have utilized task-based meth- ods, particularly working memory paradigms. Taskbased methods require participation of patients to help identify activation of brain regions thought to drive or be associated with task performances. Task-free restingstate BOLD fMRI techniques have also been used in this setting with the advantage of being able to evaluate distributed whole-brain networks without requiring overt behavioral output from subjects. ${ }^{21}$ Functional MRI studies have found persistent changes in the brain activation patterns of mild TBI patients compared with controls when given various working memory tasks. ${ }^{8,74}$ Additionally, a recent fMRI meta-analysis demonstrated a frontal vulnerability to $\mathrm{mTBI}$ as determined by decreased signal in the prefrontal cortex compared to controls. However, there is currently insufficient evidence that fMRI based on BOLD techniques are useful in the routine clinical diagnosis and/or prognosis of TBI. ${ }^{21}$

PET measures cerebral metabolism using different tracers, most commonly ${ }^{18} \mathrm{~F}$-fluorodeoxyglucose $\left({ }^{18} \mathrm{~F}\right.$ FDG), an analogue of glucose. ${ }^{18} \mathrm{~F}$-FDG measures regional glucose uptake, which should correspond to neuronal viability. PET can also be used in patients with DAI to determine the extent of damage and prognosis since DAI results in diffuse hypometabolism. ${ }^{103,104}$ The major limitation of PET imaging is that it cannot distinguish between functional abnormalities associated or unassociated with structural damage. In general, studies have found that
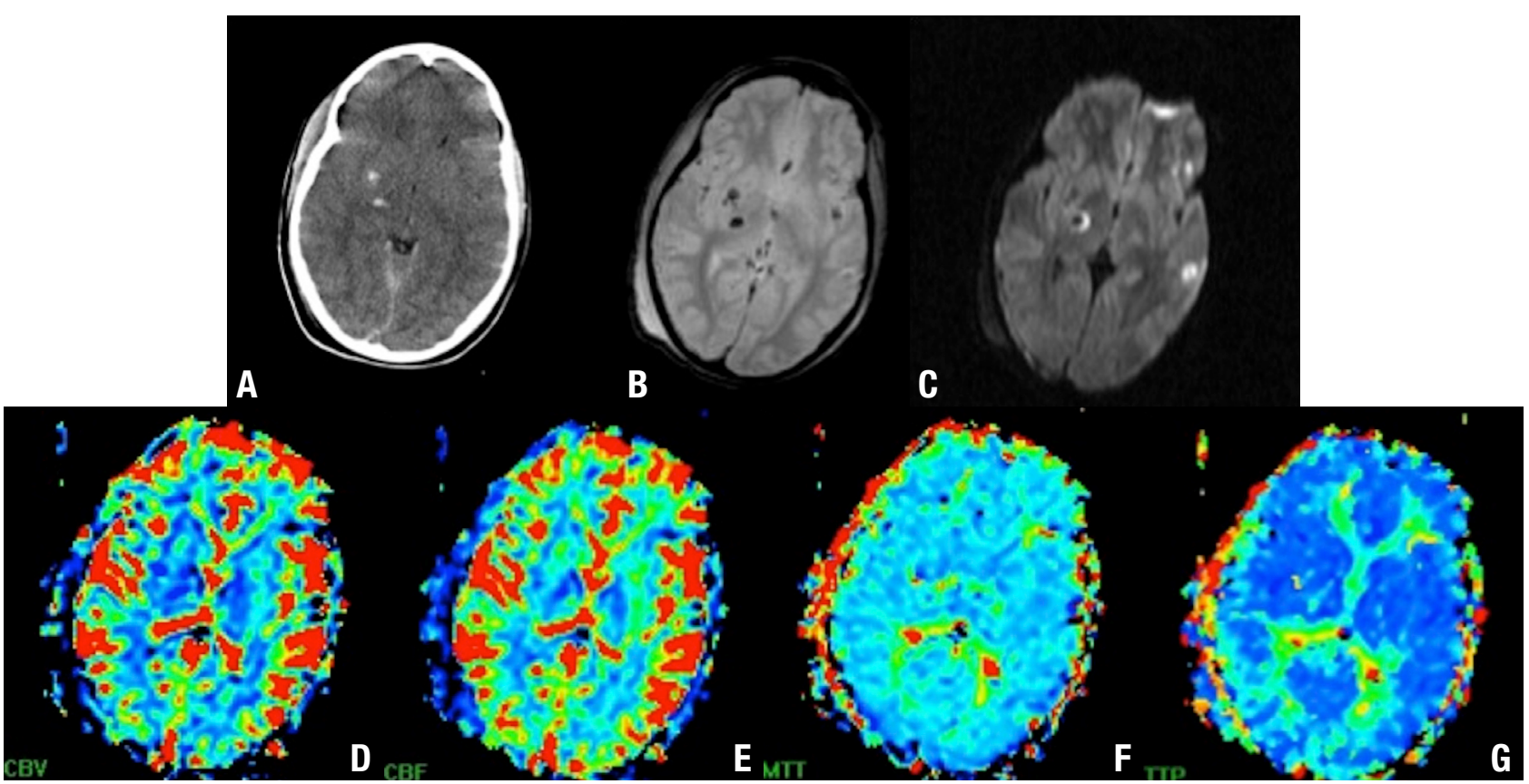

Figure 7. DAl involving the basal ganglia and gray-white matter junction. Axial CT $[A], T 2$ GRE $[B]$ and DWI $[C]$ show hemorrhagic DAl lesions. Perfusion (dynamic susceptibility contrast) MR imaging cerebral blood volume (CBV) [D], cerebral blood flow (CBF) [E], mean transit time (MTT) [F], and time to peak (TTP) [G] maps show low perfusion at the level of the basal ganglia. 
cerebral dysfunction can extend far beyond the boundary of anatomical lesions and may even appear in locations remote from the trauma. Alavi et al. ${ }^{103}$ found that GCS scores of 13 and lower were associated with whole brain hypometabolism on ${ }^{18} \mathrm{~F}$-FDG PET. Additionally, areas of PET cerebral hypometabolism that have no correlates on conventional CT or MRI, are associated with neurologi$\mathrm{cal}$ and behavioral dysfunction. ${ }^{105,106}$ Moreover, some of these areas can develop structural abnormalities such as encephalomalacia and atrophy on CT. However, PET imaging can also disclose other potentially confounding neuropsychiatric conditions such as depression or drug induced effects. ${ }^{8}$

SPECT can detect abnormalities in cerebral blood flow (CBF). However, it is not always clear whether the abnormalities observed on SPECT correspond to direct or indirect injuries or possibly abnormalities from prior trauma or other neuropsychiatric conditions. CBF abnormalities are commonly seen in mild TBI patients with chronic symptoms even when no structural damage is apparent. ${ }^{8,107}$

Very few PET and SPECT studies to date have gone beyond $\mathrm{CBF}$ and metabolic mapping to incorporate specific ligands for exploring TBI-related changes. Recent PET amyloid imaging suggests that amyloid levels rise in persons with TBI. ${ }^{36} \mathrm{~A}$ small study with a combined amyloid tau tracer showed higher levels in patients with TBI. ${ }^{37}$ Beta amyloid deposition, while seen in $40 \%-45 \%$ of chronic traumatic encephalopathy, is not as common as tau accumulation. ${ }^{21,108}$

Only a few studies have used MEG to evaluate the effects of TBI, therefore, more work is necessary to define the utility and capabilities of this imaging technique. ${ }^{21}$

\section{BIOMARKERS FOR TBI}

Over the last decade, there have been numerous studies exploring promising biomarkers of TBI. Despite the large number of publications on this subject there is still no FDA-approved biomarkers for clinical use and further research is needed to introduce them into the clinical setting. ${ }^{16}$

\section{BIOMARKERS OF ASTROGLIAL INJURY}

$S 100 \beta$ is considered a marker of astrocyte injury or death. Elevated S100 $\beta$ levels in serum have been associated with increased incidence of post concussive syndrome and cognitive deficits. ${ }^{6}$ However, there is a concern about the specificity of $S 100 \beta$ and its utility in the setting of multiple trauma remains controversial since it is also elevated in trauma patients without head injuries. ${ }^{16,109,110}$
Glial fibrillary acidic protein (GFAP) might be a useful marker for various types of brain damage including neurodegenerative disorders, stroke, and severe TBI. ${ }^{109,111,112}$ In a study by Papa et al. in 2012, ${ }^{113}$ GFAP was detectable in serum less than 1 hour after a concussion and was able to distinguish concussion patients from other trauma patients without head injury. ${ }^{16}$

\section{BIOMARKERS OF NEURONAL INJURY}

Neuron-specific enolase (NSE) has been shown be elevated after cell injury. In the setting of DAI in severe TBI, levels of NSE at 72 hours after injury have shown an association with unfavorable outcomes. ${ }^{114}$ One of the limitations of NSE is the occurrence of false-positive results in the setting of hemolysis. ${ }^{16}$

A promising candidate biomarker for TBI currently under investigation is ubiquitin C-terminal hydrolase-L1 (UCH- L1). Clinical studies in humans with severe TBI have confirmed that the UCH-L1 protein is significantly elevated in human cerebrospinal fluid (CSF) ${ }^{115}$ is detectable very early after injury, and remains significantly elevated for at least 1 week post-injury. ${ }^{115}$ More recently, $\mathrm{UCH}-\mathrm{L} 1$ was detected in the serum of mild and moderate TBI patients within one hour of injury. ${ }^{113}$ Serum levels of UCH-L1 discriminated concussion patients from uninjured and non-head-injured trauma control patients that had orthopedic injuries or motor vehicle trauma without head injury.

\section{BIOMARKERS OF AXONAL INJURY}

Alpha-II spectrin $(280 \mathrm{kDa})$ is the major structural component of the cortical membrane cytoskeleton and particularly abundant in axons, and presynaptic terminals of spectrin breakdown products (SBDPs) have been reported in the cerebrospinal fluid (CSF) of adults with severe TBI and shown a significant relationship with severity of injury and clinical outcome. ${ }^{16,111,116-118}$

Tau is an intracellular, microtubule-associated protein that is highly enriched in axons and involved with assembling axonal microtubule bundles and participating in anterograde axoplasmic transport. Because tau is preferentially located in the axon, tau lesions are apparently related to axonal disruption. ${ }^{16}$

Neurofilaments are heteropolymeric components of the neuron cytoskeleton that consist of a $68-\mathrm{kDa}$ light neurofilament subunit (NF-L) backboned with either $160-\mathrm{kDa}$ medium (NF-M) or $200-\mathrm{kDa}$ heavy subunit (NF-H) side arms. After TBI, calcium influx into the cells contributes to a cascade of events that activates calcineurin, a calcium-dependent phosphatase that dephosphorylates neurofilament side arms, presumably contributing 
to axonal injury. ${ }^{26}$ Phosphorylated NF-H has been found to be elevated in the CSF of adult patients with severe TBI compared with controls. ${ }^{119}$

Although research in the field of TBI biomarkers has increased exponentially over the past 20 years, most studies have focused on severe TBI rather than on mTBI. Because more than $80 \%$ of patients have mTBI there is a need to explore biomarkers in this population. ${ }^{16}$

\section{OUTCOME}

Dementia varies widely depending on the cause, age at diagnosis and coexisting health conditions. Post-traumatic dementia is a progressive disorder that worsens over time. Functional outcome depends on how many neurons are preserved after injury. However, the location of damage and the ability of existing neurons to reorganize their connections to recover function are also critical in determining outcomes. ${ }^{8}$

Aside from obvious cases of devastating injuries, a consistent relationship between MRI lesions and clinical or neuropsychological outcomes has not been demonstrated. ${ }^{8}$ In fact, neither CT nor MR imaging findings predict neurocognitive deficits shortly after injury or at 1-year follow-up. Thus, early imaging findings are not predictive of clinical outcome. ${ }^{120}$

SPECT appears to be better than CT or MR imaging for determining long-term prognosis. A negative initial SPECT scan after trauma strongly predicts a favorable clinical outcome ${ }^{121}$ whereas abnormal SPECT is predictive of neuro-psychological deficits. ${ }^{122}$ However, no consistent correlation between SPECT abnormalities and neuropsychological test scores has been established. ${ }^{123}$ Because MR imaging detects lesions missed by SPECT and vice versa, a combination of MR imaging and SPECT may be best for determining prognosis. ${ }^{8}$

Additionally, by combining different biomarkers from blood with MR imaging biomarkers it may be possible to delineate specific types of brain injury involved in mTBI as well as how they change over time and what the evolution of secondary damage or progression of different types of injuries is over time. ${ }^{19}$

\section{CONCLUSION}

There is no known strategy to reduce the possible longterm risks of dementia after a moderate or severe TBI, repeated mild TBIs or even after sub-concussive events, but is important to note that not all individuals who experience head injury develop dementia.

New advanced imaging tools are particularly important for investigating brain pathology in post-traumatic dementia where conventional MR and CT imaging have been found to be insufficient. However, these new techniques are still in the research stage and further investigations are needed before introducing them into clinical routine.

Authors contributions. All authors contributed equally in manuscript preparation.

\section{REFERENCES}

1. Shively S, Scher Al, Perl DP, Diaz-Arrastia R. Dementia Resulting From Traumatic Brain Injury. Arch Neurol 2012;69:1245-1251.

2. Parizel PM, Ozsarlak, Van Goethem JW, et al. Imaging findings in diffuse axonal injury after closed head trauma. Eur Radiol 1998;8:960-965.

3. Stein SC, Ross SE. Clinical predictors of abnormality disclosed by computed tomography after mild head trauma. Neurosurgery 1993;33: 339-340.

4. Moran SG, McCarthy MC, Uddin DE, Poelstra RJ. Predictors of positive CT scans in the trauma patient with minor head injury. Am Surg 1994;60:533-535-discussion535-536.

5. Duus BR, Lind B, Christensen $\mathrm{H}$, Nielsen OA. The role of neuroimaging in the initial management of patients with minor head injury. Ann Emerg Med 1994;23:1279-1283.

6. Ingebrigtsen T, Romner B. Management of minor head injuries in hospitals in Norway. Acta Neurol Scand 1997;95:51-55.

7. Schunk JE, Rodgerson JD, Woodward GA. The utility of head computed tomographic scanning in pediatric patients with normal neurologic examination in the emergency department. Pediatr Emerg Care 1996; 12:160-165.

8. Lee B, Newberg A. Neuroimaging in traumatic brain imaging. NeuroRx 2005;2:372-383

9. Traumatic Brain Injury(TBI). A topic in the Alzheimer's Association series on understanding dementia (http://www.alz.org/dementia/downloads/ topicsheet_tbi.pdf)

10. Martland H. Dementia pugilistica. JAMA 1928;91:1103-1107.

11. McKee AC, Cantu RC, Nowinski CJ, et al. Chronic traumatic encephalopathy in athletes: progressive tauopathy after repetitive head injury. J Neuropathol Exp Neurol 2009;68:709-735.

12. McKee AC, Gavett BE, Stern RA, et al. TDP-43 proteinopathy and motor neuron disease in chronic traumatic encephalopathy. J Neuropathol Exp Neurol 2010;69:918-929.

13. Hyder AA, Wunderlich CA, Puvanachandra P, Gururaj G, Kobusingye $\mathrm{OC}$. The impact of traumatic brain injuries: a global perspective. NeuroRehabilitation 2007;22:341-353.

14. Langlois JA, Rutland-Brown W, Wald MM. The epidemiology and impact of traumatic brain injury: a brief overview. J Head Trauma Rehabil 2006; 21:375-378.

15. Sosin DM, Sniezek JE, Thurman DJ. Incidence of mild and moderate brain injury in the United States, 1991. Brain Inj 1996;10:47-54.

16. Papa L, Edwards D, Ramia M. Exploring Serum Biomarkers for Mild Traumatic Brain Injury. In: Kobeissy FH, editor. Brain Neurotrauma: Molecular, Neuropsychological, and Rehabilitation Aspects. Boca Raton (FL): CRC Press; 2015. Chapter 22.

17. Goldstein M. Traumatic brain injury: a silent epidemic. Ann Neurol 1990;27:327.

18. Okie S. Traumatic brain injury in the war zone. $\mathrm{N}$ Engl J Med 2005;352:2043-2047.

19. Shenton ME, Hamoda HM, Schneiderman JS, et al. A review of magnetic resonance imaging and diffusion tensor imaging findings in mild traumatic brain injury. Brain Imaging Behav 2012;6:137-192.

20. Wilde EA, Ramos MA, Yallampalli R, et al. Diffusion tensor imaging of the cingulum bundle in children after traumatic brain injury. Dev Neuropsychol 2010;35:333-351

21. Wintermark M, Sanelli PC, Anzai Y, Tsiouris AJ, Whitlow CT. Imaging Evidence and Recommendations for Traumatic Brain Injury: Conventional Neuroimaging Techniques. J Am Coll Radiol 2015;12:e1-e14. 
22. Holm L, Cassidy JD, Carroll LJ, Borg J. Summary of the WHO Collaborating Centre for Neurotrauma Task Force on Mild Traumatic Brain Injury. J Rehabil Med 2005;37:137-141.

23. Binder LM, Rohling ML, Larrabee GJ. A review of mild head trauma. Part I: Meta-analytic review of neuropsychological studies. J Clin Exp Neuropsychol 1997;19:421-431.

24. Binder LM. A review of mild head trauma. Part II: Clinical implications. J Clin Exp Neuropsychol 1997;19:432-457

25. Kahn, HA.; Sempos, CT. Attributable Risk: Statistical Methods in Epidemiology. New York, NY: Oxford University Press; 1989:72-84.

26. Büki $A$, Povlishock JT. All roads lead to disconnection?--Traumatic axonal injury revisited. Acta Neurochir (Wien) 2006;148:181-184.

27. Gennarelli TA, Thibault LE, Adams JH, Graham DI, Thompson CJ, Marcincin RP. Diffuse axonal injury and traumatic coma in the primate. Ann Neurol 1982;12:564-574.

28. Meythaler JM, Peduzzi JD, Eleftheriou E, Novack TA. Current concepts: diffuse axonal injury-associated traumatic brain injury. Arch Phys Med Rehabil 2001;82:1461-1471

29. Povlishock JT, Erb DE, Astruc J. Axonal response to traumatic brain injury: reactive axonal change, deafferentation, and neuroplasticity. J Neurotrauma 1992;9 Suppl 1:S189-200.

30. Loane DJ, Faden Al. Neuroprotection for traumatic brain injury: translational challenges and emerging therapeutic strategies. Trends Pharmaco Sci 2010;31:596-604.

31. Xiong $Y, G u$ Q, Peterson PL, Muizelaar JP, Lee CP. Mitochondrial dysfunction and calcium perturbation induced by traumatic brain injury. J Neurotrauma 1997:14:23-34.

32. Outcomes COGWAHBIIVAL-TH, Practice BOPHAPH, Institute of Medicine. Gulf War and Health: Volume 7: Long-Term Consequences of Traumatic Brain Injury. 1st ed. National Academies Press; 2009.

33. Guskiewicz KM, McCrea M, Marshall SW, et al. Cumulative effects associated with recurrent concussion in collegiate football players: the NCAA Concussion Study. JAMA 2003;290:2549-2555.

34. Marchi N, Bazarian JJ, Puvenna V, et al. Consequences of Repeated Blood-Brain Barrier Disruption in Football Players. Dhandapani KM editor. PLoS One 2013;8:e56805.

35. Gentile NT, Mclntosh TK. Antagonists of excitatory amino acids and endogenous opioid peptides in the treatment of experimental central nervous system injury. Ann Emerg Med 1993;22:1028-1034.

36. Keynes RG, Garthwaite J. Nitric oxide and its role in ischaemic brain injury. Curr Mol Med 2004:4:179-191.

37. Leker RR, Shohami E. Cerebral ischemia and trauma-different etiologies yet similar mechanisms: neuroprotective opportunities. Brain Res Brain Res Rev 2002;39:55-73.

38. Morganti-Kossmann MC, Rancan M, Stahel PF, Kossmann T. Inflammatory response in acute traumatic brain injury: a double-edged sword. Curr Opin Crit Care 2002;8:101-105

39. Johnson VE, Stewart W, Smith DH. Axonal pathology in traumatic brain injury. Exp. Neurol 2013;246:35-43.

40. Büki A, Farkas O, Doczi T, Povlishock JT. Preinjury administration of the calpain inhibitor MDL-28170 attenuates traumatically induced axonal injury. J Neurotrauma 2003;20:261-268.

41. Maxwell WL, Domleo A, McColl G, Jafari SS, Graham DI. Post-acute alterations in the axonal cytoskeleton after traumatic axonal injury. J Neurotrauma 2003;20:151-168.

42. Mayeux R, Ottman R, Maestre G, et al. Synergistic effects of traumatic head injury and apolipoprotein-epsilon 4 in patients with Alzheimer's disease. Neurology 1995;45:555-557.

43. Plassman BL, Havlik RJ, Steffens DC, et al. Documented head injury in early adulthood and risk of Alzheimer's disease and other dementias. Neurology 20000;55:1158-1166.

44. Guo Z, Cupples LA, Kurz A, et al. Head injury and the risk of AD in the MIRAGE study. Neurology 2000;54:1316-1323.

45. Bramlett HM, Dietrich WD. Quantitative structural changes in white and gray matter 1 year following traumatic brain injury in rats. Acta Neuropathol 2002;103:607-614

46. Iwata A, Chen XH, Mclntosh TK, Browne KD, Smith DH. Long-term accumulation of amyloid-beta in axons following brain trauma without peristent upregulation of amyloid precursor protein genes. J Neuropathol Exp Neurol 2002;61:1056-1068.

47. Chen X-H, Siman R, Iwata A, Meaney DF, Trojanowski JQ, Smith DH Long-term accumulation of amyloid-beta, beta-secretase, presenilin-1, and caspase- 3 in damaged axons following brain trauma. Am J Patho 2004;165:357-371.

48. Uryu K, Laurer $\mathrm{H}$, McIntosh $\mathrm{T}$, et al. Repetitive mild brain trauma accelerates Abeta deposition, lipid peroxidation, and cognitive impairment in a transgenic mouse model of Alzheimer amyloidosis. J Neurosci 2002;22:446-454.

49. Tran HT, LaFerla FM, Holtzman DM, Brody DL. Controlled cortical impact traumatic brain injury in 3xTg-AD mice causes acute intra-axonal amyloid- $\beta$ accumulation and independently accelerates the development of tau abnormalities. J Neurosci 2011;31:9513-9525.

50. Loane DJ, Pocivavsek A, Moussa CE-H, et al. Amyloid precursor protein secretases as therapeutic targets for traumatic brain injury. Nat Med 2009;15:377-379.

51. Biran Y, Masters CL, Barnham KJ, Bush Al, Adlard PA. Pharmacotherapeutic targets in Alzheimer's disease. J Cell Mol Med 2009;13:61-86.

52. Buckner RL, Sepulcre J, Talukdar T, et al. Cortical hubs revealed by intrinsic functional connectivity: mapping, assessment of stability, and relation to Alzheimer's disease. J Neurosci 2009;29:1860-1873.

53. Stein MB, McAllister TW. Exploring the convergence of posttraumatic stress disorder and mild traumatic brain injury. Am J Psychiatry 2009; 166:768-776.

54. Eierud C, Craddock RC, Fletcher S, et al. Neuroimaging after mild traumatic brain injury: Review and meta-analysis. YNICL. The Authors 2013;4:283-294.

55. Irimia A, Wang B, Aylward SR, et al. Neuroimaging of structural pathology and connectomics in traumatic brain injury: Toward personalized outcome prediction. Neuroimage Clin 2012;1:1-17.

56. Cohen BA, Inglese M, Rusinek H, Babb JS, Grossman RI, Gonen O. Proton MR spectroscopy and MRI-volumetry in mild traumatic brain injury. AJNR Am J Neuroradiol 2007;28:907-913.

57. Ding K, la Plata de CM, Wang JY, et al. Cerebral atrophy after traumatic white matter injury: correlation with acute neuroimaging and outcome. $J$ Neurotrauma 2008;25:1433-1440.

58. Gale SD, Johnson SC, Bigler ED, Blatter DD. Nonspecific white matter degeneration following traumatic brain injury. J Int Neuropsychol Soc 1995; 1:17-28.

59. Gale SD, Baxter L, Roundy N, Johnson SC. Traumatic brain injury and grey matter concentration: a preliminary voxel based morphometry study. J Neurol Neurosurg Psychiatr 2005;76:984-988

60. Levine B, Kovacevic N, Nica El, et al. The Toronto traumatic brain injury study: injury severity and quantified MRI. Neurology. 2008;70:771-778.

61. MacKenzie JD, Siddiqi F, Babb JS, et al. Brain atrophy in mild or moderate traumatic brain injury: a longitudinal quantitative analysis. AJNR Am J Neuroradiol 2002;23:1509-1515.

62. Trivedi MA, Ward MA, Hess TM, et al. Longitudinal changes in global brain volume between 79 and 409 days after traumatic brain injury: relationship with duration of coma. J Neurotrauma 2007;24:766-771.

63. Warner MA, Youn TS, Davis T, et al. Regionally selective atrophy after traumatic axonal injury. Arch Neurol 2010;67:1336-1344.

64. Yount R, Raschke KA, Biru M, et al. Traumatic brain injury and atrophy of the cingulate gyrus. J Neuropsychiatry Clin Neurosci 2002;14:416-423.

65. Bigler ED, Blatter DD, Anderson CV, et al. Hippocampal volume in norma aging and traumatic brain injury. AJNR Am J Neuroradiol 1997;18: 11-23.

66. Himanen L, Portin R, Isoniemi H, Helenius H, Kurki T, Tenovuo O. Cognitive functions in relation to MRI findings 30 years after traumatic brain injury. Brain Inj 2005:19:93-100.

67. Strangman GE, O'Neil-Pirozzi TM, Supelana C, Goldstein R, Katz DI, Glenn MB. Regional brain morphometry predicts memory rehabilitation outcome after traumatic brain injury. Front Hum Neurosci 2010;4:182-182

68. Tate DF, Bigler ED. Fornix and hippocampal atrophy in traumatic brain injury. Learn Mem 2000;7:442-446.

69. Anderson CV, Bigler ED, Blatter DD. Frontal lobe lesions, diffuse damage, and neuropsychological functioning in traumatic brain-injured patients. J Clin Exp Neuropsychol 1995:17:900-908.

70. Schönberger M, Ponsford J, Reutens D, Beare R, O'Sullivan R. The Relationship between age, injury severity, and MRI findings after traumatic brain injury. J Neurotrauma 2009;26:2157-2167.

71. Tong KA, Ashwal S, Holshouser BA, et al. Hemorrhagic shearing lesions in children and adolescents with posttraumatic diffuse axonal injury: improved detection and initial results. Radiology 2003;227:332-339.

72. Tong KA, Ashwal S, Holshouser BA, et al. Diffuse axonal injury in children: clinical correlation with hemorrhagic lesions. Ann Neurol 2004;56:36-50.

73. Hashimoto K, Abo M. Abnormal regional benzodiazepine recepto uptake in the prefrontal cortex in patients with mild traumatic brain injury. J Rehabil Med 2009;41:661-665.

74. McAllister TW, Saykin AJ, Flashman LA, et al. Brain activation during working memory 1 month after mild traumatic brain injury: a functional MRI study. Neurology 1999;53:1300-1308. 
75. Niogi SN, Mukherjee P, Ghajar J, et al. Extent of microstructural white matter injury in postconcussive syndrome correlates with impaired cognitive reaction time: a $3 \mathrm{~T}$ diffusion tensor imaging study of mild traumatic brain injury. AJNR Am J Neuroradiol 2008;29:967-973.

76. Mayer AR, Mannell MV, Ling J, Gasparovic C, Yeo RA. Functiona connectivity in mild traumatic brain injury. Hum Brain Mapp 2011;32: 1825-1835.

77. Niogi SN, Mukherjee P. Diffusion tensor imaging of mild traumatic brain injury. J Head Trauma Rehabil 2010;25:241-255.

78. Ennis DB, Kindlmann G. Orthogonal tensor invariants and the analysis of diffusion tensor magnetic resonance images. Magn Reson Med 2006;55:136-146

79. Pfefferbaum A, Sullivan EV, Hedehus M, Adalsteinsson E, Lim KO, Moseley M. In vivo detection and functional correlates of white matter microstructural disruption in chronic alcoholism. Alcohol Clin Exp Res 2000;24:1214-1221.

80. Pasternak O, Assaf Y, Intrator N, Sochen N. Variational multiple-tensor fitting of fiber-ambiguous diffusion-weighted magnetic resonance imaging voxels. Magn Reson Imaging 2008;26:1133-1144.

81. Zhang H, Schneider T, Wheeler-Kingshott CA, Alexander DC. NODDI: practical in vivo neurite orientation dispersion and density imaging of the human brain. Neurolmage 2012;61:1000-1016.

82. Tuch DS. Q-ball imaging. Magn Reson Med 2004;52:1358-1372.

83. Tournier J-D, Calamante F, Connelly A. Robust determination of the fibre orientation distribution in diffusion MRI: non-negativity constrained superresolved spherical deconvolution. Neurolmage 2007;35:1459-1472.

84. Henry LC, Tremblay S, Boulanger Y, Ellemberg D, Lassonde M. Neurometabolic changes in the acute phase after sports concussions correlate with symptom severity. J Neurotrauma 2010;27:65-76.

85. Henry LC, Tremblay S, Leclerc S, et al. Metabolic changes in concussed American football players during the acute and chronic post-injury phases. BMC Neurol 2011;11:105-115.

86. Sarmento E, Moreira P, Brito C, Souza J, Jevoux C, Bigal M. Proton spectroscopy in patients with post-traumatic headache attributed to mild head injury. Headache 2009;49:1345-1352.

87. Vagnozzi R, Signoretti S, Cristofori L, et al. Assessment of metabolic brain damage and recovery following mild traumatic brain injury: a multicentre, proton magnetic resonance spectroscopic study in concussed patients. Brain 2010;133:3232-3242.

88. Sinson G, Bagley LJ, Cecil KM, et al. Magnetization transfer imaging and proton MR spectroscopy in the evaluation of axonal injury: correlation with clinical outcome after traumatic brain injury. AJNR Am J Neuroradio 2001;22:143-151.

89. Cecil KM, Hills EC, Sandel ME, et al. Proton magnetic resonance spectroscopy for detection of axonal injury in the splenium of the corpus callosum of brain-injured patients. J Neurosurg 1998;88:795-801.

90. Garnett MR, Blamire AM, Rajagopalan B, Styles P, Cadoux-Hudson TA Evidence for cellular damage in normal-appearing white matter correlates with injury severity in patients following traumatic brain injury: A magnetic resonance spectroscopy study. Brain 2000;123:1403-1409.

91. Vagnozzi R, Signoretti S, Tavazzi B, et al. Temporal window of metabolic brain vulnerability to concussion: a pilot $1 \mathrm{H}$-magnetic resonance spectroscopic study in concussed athletes--part III. Neurosurgery 2008; 62:1286-1286

92. Govindaraju V, Gauger GE, Manley GT, Ebel A, Meeker M, Maudsley AA Volumetric proton spectroscopic imaging of mild traumatic brain injury. AJNR Am J Neuroradiol 2004;25:730-737.

93. Kirov I, Fleysher L, Babb JS, Silver JM, Grossman RI, Gonen O. Characterizing "mild" in traumatic brain injury with proton MR spectroscopy in the thalamus: Initial findings. Brain Inj 2007:21:1147-1154.

94. Govind V, Gold S, Kaliannan K, et al. Whole-brain proton MR spectroscopic imaging of mild-to-moderate traumatic brain injury and correlation with neuropsychological deficits. J Neurotrauma 2010;27:483-496.

95. Gasparovic C, Yeo R, Mannell M, et al. Neurometabolite concentrations in gray and white matter in mild traumatic brain injury: an $1 \mathrm{H}$-magnetic resonance spectroscopy study. J Neurotrauma 2009;26:1635-1643.

96. Ross BD, Ernst T, Kreis R, et al. $1 \mathrm{H}$ MRS in acute traumatic brain injury. J Magn Reson Imaging 1998;8:829-840

97. Ashwal S, Holshouser B, Tong $\mathrm{K}$, et al. Proton MR spectroscopy detected glutamate/glutamine is increased in children with traumatic brain injury. J Neurotrauma 2004;21:1539-1552.

98. Yeo RA, Gasparovic C, Merideth F, Ruhl D, Doezema D, Mayer AR. A longitudinal proton magnetic resonance spectroscopy study of mild traumatic brain injury. J Neurotrauma 2011;28:1-11.

99. Tollard E, Galanaud D, Perlbarg V, et al. Experience of diffusion tensor imaging and $1 \mathrm{H}$ spectroscopy for outcome prediction in severe traumatic brain injury: Preliminary results. Crit Care Med 2009;37:1448-1455.

100. Lexa FJ, Grossman RI, Rosenquist AC. Dyke Award paper. MR of wallerian degeneration in the feline visual system: characterization by magnetization transfer rate with histopathologic correlation. AJNR Am J Neuroradiol 1994;15:201-212.

101. Kimura H, Meaney DF, McGowan JC, et al. Magnetization transfer imaging of diffuse axonal injury following experimental brain injury in the pig: characterization by magnetization transfer ratio with histopathologic correlation. J Comput Assist Tomogr 1996;20:540-546.

102. Bagley LJ, McGowan JC, Grossman RI, et al. Magnetization transfer imaging of traumatic brain injury. J Magn Reson Imaging. 2000;11:1-8.

103. Alavi A. Functional and anatomic studies of head injury. J Neuropsychiatry Clin Neurosci 1989;1:S45-50.

104. Langfitt TW, Obrist WD, Alavi A, et al. Computerized tomography, magnetic resonance imaging, and positron emission tomography in the study of brain trauma. Preliminary observations. J Neurosurg 1986;64:760-767

105. Humayun MS, Presty SK, Lafrance ND, et al. Local cerebral glucose abnormalities in mild closed head injured patients with cognitive impairments. Nucl Med Commun 1989;10:335-344.

106. Rao N, Turski PA, Polcyn RE, Nickels RJ, Matthews CG, Flynn MM. 18F positron emission computed tomography in closed head injury. Arch Phys Med Rehabil 1984;65:780-785.

107. Bonne O, Gilboa A, Louzoun Y, et al. Cerebral blood flow in chronic symptomatic mild traumatic brain injury. Psychiatry Res 2003;124: 141-152.

108. Zink BJ. Traumatic brain injury. Emerg Med Clin North Am 1996;14: 115-150.

109. Pelinka LE, Kroepfl A, Schmidhammer R, et al. Glial fibrillary acidic protein in serum after traumatic brain injury and multiple trauma. J Trauma 2004;57:1006-1012

110. Rothoerl RD, Woertgen C, Holzschuh M, Metz C, Brawanski A. S-100 serum levels after minor and major head injury. J Trauma 1998; 45:765-767

111. Mondello S, Robicsek SA, Gabrielli A, et al. $\alpha$ ll-spectrin breakdown products (SBDPs): diagnosis and outcome in severe traumatic brain injury patients. J Neurotrauma 2010;27:1203-1213.

112. Nylén $K$, Ost M, Csajbok LZ, et al. Increased serum-GFAP in patients with severe traumatic brain injury is related to outcome. J Neurol Sci 2006:240:85-91.

113. Papa L. Exploring the Role of Biomarkers for the Diagnosis and Management of Traumatic Brain Injury Patients. 2012.

114. Chabok SY, Moghadam AD, Saneei Z, Amlashi FG, Leili EK, Amiri ZM. Neuron-specific enolase and S100BB as outcome predictors in severe diffuse axonal injury. J Trauma Acute Care Surg 2012;72:1654-1657.

115. Papa L, Akinyi L, Liu MC, et al. Ubiquitin C-terminal hydrolase is a novel biomarker in humans for severe traumatic brain injury. Crit Care Med 2010;38:138-144

116. Cardali S, Maugeri R. Detection of alphall-spectrin and breakdown products in humans after severe traumatic brain injury. J Neurosurg Sci 2006;50:25-31

117. Farkas O, Polgár B, Szekeres-Barthó J, Doczi T, Povlishock JT, Büki A. Spectrin breakdown products in the cerebrospinal fluid in severe head injury-preliminary observations. Acta Neurochir (Wien) 2005; 147:855-861.

118. Pineda JA, Lewis SB, Valadka AB, et al. Clinical significance of alphallspectrin breakdown products in cerebrospinal fluid after severe traumatic brain injury. J Neurotrauma 2007;24:354-366.

119. Siman R, Toraskar N, Dang A, et al. A panel of neuron-enriched proteins as markers for traumatic brain injury in humans. J Neurotrauma 2009:26:1867-1877.

120. Provenzale JM. Imaging of Traumatic Brain Injury: A Review of the Recent Medical Literature. Am J Roentgenol 2010;194:16-19.

121. Jacobs $A$, Put $E$, Ingels $M$, Put $T$, Bossuyt $A$. One-year follow-up of technetium-99m-HMPAO SPECT in mild head injury. J Nucl Med 1996; 37:1605-1609.

122. Baulieu F, Fournier P, Baulieu JLW, et al. Technetium-99m ECD single photon emission computed tomography in brain trauma: comparison of early scintigraphic findings with long-term neuropsychological outcome. J Neuroimag 2001;11:112-220.

123. Radanov BP, Bicik I, Dvorak J, Antinnes J, Schulthess von GK, Buck A. Relation between neuropsychological and neuroimaging findings in patients with late whiplash syndrome. J Neurol Neurosurg Psychiatr 1999;66:485-489. 